\title{
The Effect of Learning Goal Orientation on Academic Satisfaction based on the Perspective of Social Cognitive Theory
}

\author{
Xiaodi Zhang \\ AIEN Institute, Shanghai Ocean University, Shanghai, China \\ julict@126.com
}

\begin{abstract}
Based on the perspective of social cognitive theory, this study conducted a questionnaire survey on academic satisfaction of 302 college students, and investigated the mechanism of learning goal orientation on academic satisfaction by using correlation analysis and regression analysis. It was found that: both learning goal orientation and academic Self-efficacy had a significant positive effect on academic satisfaction; academic Self-efficacy mediated the relationship between learning goal orientation and academic satisfaction; teachers' academic support partially moderated the positive relationship between learning goal orientation and academic satisfaction. The empirical results of this study provide a reference for universities and college students to improve learning goal orientation and academic satisfaction by themselves.
\end{abstract}

Keywords: Social Cognitive Theory; Learning Goal Orientation; Academic Self-efficacy; Academic Satisfaction; Academic Support from Teachers.

\section{Introduction}

In recent years, the physical and mental development of students has received more and more attention from the educational community, which advocates that students should learn with pleasure, so the academic satisfaction of students should not be underestimated [1]. Academic satisfaction is inseparable from students' physical and mental development, and it not only restricts college students' motivation to study, but also affects their psychological health level [2]. The importance of academic satisfaction as a predictor of students' psychological health [3] cannot be overstated. Academic satisfaction refers to students' satisfaction with their academic performance and learning performance during their school years [4], which can be further divided into learning satisfaction, teaching satisfaction and school hardware satisfaction [5]. Academic satisfaction is an important measure of the extent to which university teaching responds to the needs of society and the quality of teaching in higher education institutions [6]. Studies have shown that the level of Self-efficacy, the availability of reasonable learning goals and strategies, and teachers' teaching may affect academic satisfaction [1]. However, there are few studies on academic satisfaction and few studies on how learning goal orientation and academic Self-efficacy affect academic satisfaction, so it is of great practical value to conduct research on the factors and mechanisms influencing academic satisfaction [7].

Existing studies have found that learning goal orientation is an important factor influencing students' academic satisfaction [8], and thus learning goal orientation deserves further research. Learning goal orientation refers to the ability of individuals to develop themselves by continuously learning new skills, successfully coping with new situations, and learning from experience [8]. Learning goal orientation is a notable motivational agency idea that is associated with positive academic performance [9]. In the view of learning goal-oriented individuals, competencies can be developed through effort and success can be achieved by putting in the effort [10].

In previous studies by domestic and foreign scholars, fewer studies have been conducted on learning goal orientation and academic satisfaction using academic Self-efficacy as a mediating variable. Foreign studies have focused on psychological capital as an explanatory mechanism to explore the mechanism of the role of learning goal orientation on academic satisfaction [8]. Related studies have shown that learning goal orientation and academic satisfaction are highly susceptible to contextual and individual factors such as learning environment, Self-efficacy, and learning attitudes 
[5] [10], and that students are more likely to have positive academic emotions and show higher academic satisfaction in organizational contexts where teachers provide academic support. There are no studies that have examined the impact of learning goal orientation on academic satisfaction through academic Self-efficacy from a social cognitive theory perspective. Therefore, this paper takes the perspective of social cognitive theory as a novel starting point.

Based on the above analysis, this study attempts to explore the path of learning goal orientation on college students' academic satisfaction and the role of academic Self-efficacy in this path, and observe its effect on the relationship between learning goal orientation and academic Self-efficacy using teachers' academic support as the boundary condition, which provides a reference basis for colleges and universities and college students themselves to improve their academic satisfaction.

\section{Research Design}

\subsection{Research Hypothesis}

\subsubsection{Learning Goal Orientation and Academic Satisfaction}

A large number of empirical studies have demonstrated a positive relationship between learning goal orientation and academic satisfaction. Learning goal orientation is associated with setting higher goals and maintaining higher performance over time [11]. In a study conducted by Roebken on undergraduate students to explore the relationship between learning goal orientation and academic satisfaction, academic engagement, and achievement, the results showed that students with high learning goal orientation presented higher academic satisfaction as well as academic performance [12]. On the other hand, Dweck found that satisfaction with the outcome depends on the effort put by the individual in the pursuit of the goal [13]. While for individuals who are learning goal oriented, they are more inclined to stay focused on the task when facing difficulties, put great effort in the process of work and believe that the effort will be rewarded with success, thus VandeWalle et al. concluded that learning goal orientation is associated with high levels of effort [14], which in turn promotes individual satisfaction with the outcome. Therefore, based on the above analysis, this paper proposes the following research hypotheses.

$\mathrm{H} 1$ : Learning goal orientation is positively related to academic satisfaction

\subsubsection{Learning Goal Orientation and Academic Self-efficacy}

Bandura's social cognitive theory suggests that human activity is influenced and mutually determined by three factors: the individual's cognition, behavior, and the context in which he or she is placed [15]. Self-efficacy is a central element in social cognitive theory [16]. Self-efficacy is an individual's expectation of his or her beliefs about his or her ability to perform a particular behavior or to complete the behavior required to lead to a certain outcome [17]. Academic Self-efficacy, on the other hand, is a specific manifestation of Self-efficacy in the context of learning. Learning goaldirected individuals are more likely to develop their abilities by accumulating learning experiences over time, either directly or indirectly [18], whereas individual Self-efficacy is based on prior experiences [16]. Therefore, learning goal-oriented individuals are more likely to maintain a higher sense of academic Self-efficacy. Based on the above analysis, this paper proposes the following hypothesis.

H2: Learning goal orientation is positively related to academic Self-efficacy

\subsubsection{Academic Self-efficacy and Academic Satisfaction}

In the study of the relationship between social support, Self-efficacy and academic achievement and academic satisfaction, Sivandani et al. found that students with high levels of Self-efficacy tended to work harder and were able to achieve more satisfactory grades through their efforts, thus increasing their academic satisfaction [19]. In addition, Artino also found a significant correlation between Selfefficacy and academic satisfaction in his study [20]. In their study of general Self-efficacy and social anxiety among college students, Fu Mei et al. found that increasing Self-efficacy could alleviate social 
anxiety and thus increase college students' academic satisfaction [21]. Zhang concluded that high academic Self-efficacy can enhance students' effort in learning, which leads to positive academic attitudes [22]. Through their study, Xie Li et al. found that the level of academic Self-efficacy largely influenced the emotional responses and academic performance of college students [23]. For college students, successful completion of their studies is a priority, and their beliefs about their ability to complete their studies are closely related to their academic performance, which is directly related to students' academic satisfaction [24]. As a result, the following hypothesis is proposed.

H3: Academic Self-efficacy is positively related to academic satisfaction

\subsubsection{The Mediating Role of Academic Self-efficacy}

On the one hand, learning goal-oriented individuals are willing to treat difficulties as opportunities [25], and they believe that ability can be grown through continuous learning [8]. Moreover, they attribute setbacks to insufficient effort rather than ability problems, and thus such individuals can consistently maintain a high level of academic Self-efficacy [26]. On the other hand, because learning goal-oriented individuals believe that ability can be changed through effort, they exert more effort [26]. Related studies have found that academic Self-efficacy sustains students' efforts and makes them productive in their learning [27], thus increasing academic satisfaction. This led to the following hypothesis.

H4: Academic Self-efficacy plays a mediating role in the positive relationship between learning goal orientation and academic satisfaction

\subsubsection{Moderating Role of Teachers' Academic Support}

Teacher academic support refers to teachers who care and guide students academically, give them understanding, respect and recognition, and are able to treat each student fairly [28]. On the one hand, teachers can help students stay focused on tasks, including those that are challenging, by creating contexts or giving feedback. On the other hand, teachers can also provide opportunities for students to ask questions and help them select or create resources that help them solve problems and develop strategies [27]. When students feel high academic support from teachers, they tend to develop a sense of belonging and identity, which in turn enhances academic initiative [29]. According to selfdetermination theory, psychological needs are one of the three major needs of students. High academic support from teachers helps to meet students' psychological needs and motivates students to maintain positive academic attitudes and thus experience fewer negative academic emotions. A decrease in negative academic emotions can contribute to an increase in students' academic Selfefficacy [30]. Based on the above analysis, the following research hypothesis is proposed in this paper.

H5: Teacher academic support moderates the relationship between learning goal orientation and academic Self-efficacy, and the higher the teacher academic support, the more significant the positive relationship between learning goal orientation and academic Self-efficacy

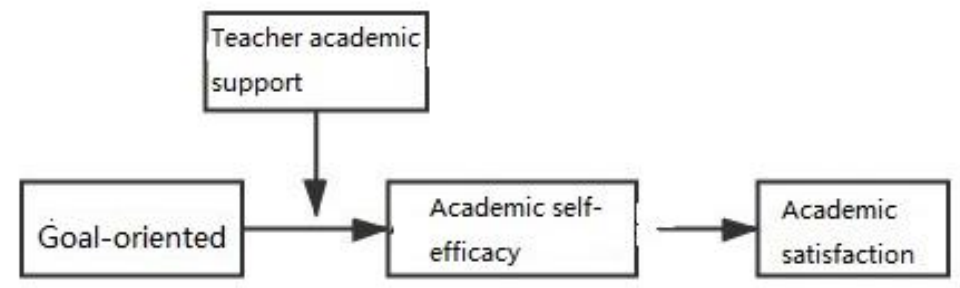

Figure 1. Conceptual model

\section{Research Methodology}

\subsection{Sample and Data Collection}

The research samples were mainly from major universities in Jiangsu, Shanghai, Anhui and Sichuan. The data were collected by creating online questionnaires and using online anonymous surveys, and the respondents were assured that the survey results were only used for academic 
research. A total of 330 questionnaires were distributed, of which 302 were valid, with a valid return rate of $91.52 \%$. In terms of gender, $38.74 \%$ were male and $61.26 \%$ were female; in terms of grade, $17.55 \%$ were freshmen, $19.87 \%$ were sophomores, $33.11 \%$ were juniors, $22.85 \%$ were seniors, and $6.62 \%$ were postgraduates and above; in terms of ethnicity, $83.11 \%$ were Han Chinese and $16.89 \%$ were ethnic minorities; $49.01 \%$ were only children and $50.99 \%$ were non-children. As for household registration, $61.92 \%$ were urban households and $38.08 \%$ were rural households.

\subsection{Measurement Tools}

The variable measurement instruments in this study were selected from the Chinese and English maturity scales, and the final questionnaire was formed by translating and revising several times to ensure their validity and reliability. In this study, all scale items were measured using the Likert 7 point method.

(1) Learning goal orientation

In this paper, this variable was measured using the Learning Goal Orientation subscale of the Achievement Goal Orientation Scale developed by VandeWalle [31]. The scale consists of five questions, such as "I would like to choose challenging learning tasks where I can learn a lot". The Cronbach's alpha value of this scale was 0.891 .

(2) Academic Self-efficacy

In this paper, we refer to the general Self-efficacy scale developed by Schwarzer [32] and modify it appropriately, with a total of 10 questions, such as "If I put in the necessary effort, I will be able to solve my academic problems. The Cronbach's alpha value of this scale was 0.933 .

(3) Academic satisfaction

In this paper, we refer to the satisfaction scale developed by Alberto and Marisa [33], which consists of four questions, such as "Overall, I am satisfied with my university". The Cronbach's alpha value of this scale is 0.879 .

(4) Teacher academic support

In this paper, the scale developed by Overall et al [34] was used as a reference for the academic support section, with 10 questions, such as "My teacher will provide practical advice on how to move forward with my research". The Cronbach's alpha value for this scale was 0.950 .

(5) Control variables

In this study, students' gender, grade level, ethnicity, whether they are only child, and household registration were used as control variables in this paper.

\section{Research Results}

\subsection{Control and Validation of Common Method Bias Test}

To prevent common method bias, firstly, this study followed the principle of voluntary participation by sending and receiving questionnaires online and allowing students to fill them out anonymously online. Secondly, each section of the questionnaire was designed with different guiding words to separate the different scales.

Despite these measures, there is still a possibility of common method bias because each returned questionnaire in this study came from the same respondent. Therefore, the Harman one-way test was further used to test them in this study. The first principal component obtained without rotation was $37.301 \%$, which is less than $40 \%$ of the total explained variance, and it can be concluded that the problem of common method bias in this study is not serious.

\subsection{Confirmatory Factor Analysis}

In order to test the discriminant validity of the study variables, this study used Lisrel870 software to conduct confirmatory factor analysis on four variables: learning goal orientation, academic Selfefficacy, academic satisfaction, and teacher academic support, and the results are shown in Table 1. 0.977, $\mathrm{CFI}=0.987, \mathrm{RFI}=0.974, \mathrm{SRMR}=0.035$ ), and significantly better than the other nested models, 
indicating that the four-factor theoretical model can represent the corresponding research constructs and has good discriminant validity.

Table 1. Results of the confirmatory factor analysis $(\mathrm{N}=302)$

\begin{tabular}{|c|c|c|c|c|c|c|c|c|c|}
\hline Models & $\chi^{2}$ & $\mathrm{df}$ & $\chi^{2} / \mathrm{df}$ & RMSEA & SRMR & NFI & CFI & IFI & RFI \\
\hline $\begin{array}{c}\text { Four-factor } \\
\text { model }\end{array}$ & 783.823 & 371 & 2.113 & 0.061 & 0.035 & 0.977 & 0.987 & 0.987 & 0.974 \\
\hline $\begin{array}{c}\text { Three-factor } \\
\text { model }\end{array}$ & 1214.147 & 374 & 3.246 & 0.086 & 0.051 & 0.969 & 0.979 & 0.979 & 0.967 \\
\hline $\begin{array}{c}\text { Two-factor } \\
\text { model }\end{array}$ & 2057.093 & 376 & 5.471 & 0.122 & 0.058 & 0.960 & 0.970 & 0.970 & 0.957 \\
\hline $\begin{array}{c}\text { One-factor } \\
\text { model }\end{array}$ & 2157.726 & 377 & 5.723 & 0.125 & 0.059 & 0.958 & 0.968 & 0.968 & 0.955 \\
\hline
\end{tabular}

Note: The criteria for evaluating the goodness of fit of indicators were: $\chi^{2} / \mathrm{df}<3$, RMSEA $<0.08$, SRMR $<0.05$, $\mathrm{NFI}>0.9, \mathrm{CFI}>0.9$, IFI $>0.9$, and RFI $>0.9$.

Four-factor model: learning goal orientation, teacher academic support, academic Self-efficacy, and academic satisfaction;

Three-factor model: learning goal orientation + teacher academic support, academic Self-efficacy, academic satisfaction;

Two-factor model: learning goal orientation + teacher academic support + academic Self-efficacy, academic satisfaction;

One-factor model: learning goal orientation + teacher academic support + academic Self-efficacy + academic satisfaction.

\subsection{Descriptive Statistics and Correlation Analysis}

The means, standard deviations and correlation coefficients of the variables and the significance levels are shown in Table 2. As shown in Table 2, none of the values showed abnormalities, and there was a significant positive correlation between learning goal orientation and academic Self-efficacy $(\mathrm{r}=0.821, \mathrm{p}<0.01)$ and academic satisfaction $(\mathrm{r}=0.758, \mathrm{p}<0.01)$, and academic Self-efficacy and academic satisfaction $(\mathrm{r}=0.729, \mathrm{p}<0.01)$ also showed a significant positive correlation. This provides preliminary evidence for hypothesis testing and suggests that further hypothesis testing can be conducted.

Table 2. Means, standard deviations, and correlation coefficients for each variable $(\mathrm{N}=302)$

\begin{tabular}{|c|c|c|c|c|c|c|c|c|c|c|c|}
\hline & Variable & Mean & SD & 1 & 2 & 3 & 4 & 5 & 6 & 7 & 8 \\
\hline 1 & Gender & 1.610 & 0.488 & & & & & & & & \\
\hline 2 & Grade & 2.810 & 1.167 & 0.104 & & & & & & & \\
\hline 3 & Ethnicity & 1.170 & 0.375 & 0.014 & 0.043 & & & & & & \\
\hline 4 & $\begin{array}{c}\text { Only child or } \\
\text { not }\end{array}$ & 1.510 & 0.501 & -0.059 & 0.034 & 0.053 & & & & & \\
\hline 5 & $\begin{array}{l}\text { Household } \\
\text { registration }\end{array}$ & 1.380 & 0.486 & 0.064 & 0.051 & -0.008 & $0.128^{*}$ & & & & \\
\hline 6 & $\begin{array}{c}\text { Learning goal } \\
\text { orientation }\end{array}$ & 5.034 & 1.296 & 0.004 & -0.059 & 0.070 & -0.048 & -0.038 & & & \\
\hline 7 & $\begin{array}{c}\text { Academic Self- } \\
\text { efficacy }\end{array}$ & 4.973 & 1.252 & -0.038 & -0.038 & $0.131^{*}$ & -0.031 & -0.019 & $0.821^{* *}$ & & \\
\hline $\begin{array}{l}8 \\
9\end{array}$ & $\begin{array}{c}\text { Teachers' } \\
\text { academic } \\
\text { support }\end{array}$ & $\begin{array}{l}5.015 \\
5.045\end{array}$ & $\begin{array}{l}1.368 \\
1.366\end{array}$ & $\begin{array}{l}-0.004 \\
-0.023\end{array}$ & $\begin{array}{l}-0.059 \\
-0.020\end{array}$ & $\begin{array}{c}0.116^{*} \\
0.031\end{array}$ & $\begin{array}{c}0.004 \\
-0.043\end{array}$ & $\begin{array}{c}0.021 \\
-0.004\end{array}$ & $\begin{array}{l}0.759^{* * *} \\
0.758^{* *}\end{array}$ & $\begin{array}{l}0.762^{* * *} \\
0.729^{* *}\end{array}$ & $0.848^{* *}$ \\
\hline
\end{tabular}

\subsection{Hypothesis Testing}

First, this paper used hierarchical regression analysis to initially test the main effect of learning goal orientation on academic satisfaction, the mediating role of academic Self-efficacy, and the 
moderating effect of teachers' academic support, and the results are shown in Table 3; then the moderating effect of teachers' academic support was tested with the help of Bootstrap test.

For the test of main effects, it can be seen from model 6 in Table 3 that after controlling for demographic variables such as student gender and grade level, learning goal orientation has a significant positive effect on academic satisfaction $(\beta=0.762, p<0.01)$, and therefore, H1 is supported.

Table 3. Regression analysis results

\begin{tabular}{|c|c|c|c|c|c|c|c|c|}
\hline \multirow{2}{*}{ Variable } & \multicolumn{4}{|c|}{ Academic Self-efficacy } & \multicolumn{4}{|c|}{ Academic satisfaction } \\
\hline & Model1 & Model 2 & Model 3 & Model 4 & Model 5 & Model 6 & Model 7 & Model 8 \\
\hline Gender & -0.037 & -0.045 & -0.042 & -0.043 & -0.024 & -0.031 & 0.003 & -0.016 \\
\hline Grade & -0.038 & 0.011 & 0.018 & 0.023 & -0.018 & 0.028 & 0.010 & 0.024 \\
\hline Ethnicity & $0.135^{*}$ & $0.074^{*}$ & 0.054 & 0.060 & 0.034 & -0.023 & -0.065 & -0.047 \\
\hline $\begin{array}{l}\text { Only child } \\
\text { or not }\end{array}$ & -0.038 & -0.001 & -0.011 & -0.002 & -0.046 & -0.012 & -0.018 & -0.011 \\
\hline $\begin{array}{l}\text { Household } \\
\text { registration }\end{array}$ & -0.008 & 0.015 & 0.000 & 0.001 & 0.004 & 0.026 & 0.010 & 0.021 \\
\hline $\begin{array}{l}\text { Learning } \\
\text { Goal } \\
\text { Orientation }\end{array}$ & & $0.817^{* * * *}$ & $0.574^{* * * *}$ & $0.534^{* * *}$ & & $0.762^{* * * *}$ & & $0.486^{* * *}$ \\
\hline $\begin{array}{c}\text { Teacher } \\
\text { academic } \\
\text { support }\end{array}$ & & & $0.321^{* * * *}$ & $0.285^{* * *}$ & & & & \\
\hline $\begin{array}{l}\text { Learning } \\
\text { goal } \\
\text { orientation } \mathrm{x} \\
\text { teacher } \\
\text { academic } \\
\text { support } \\
\end{array}$ & & & & $-0.102^{*}$ & & & & \\
\hline $\begin{array}{c}\text { Academic } \\
\text { Self-efficacy }\end{array}$ & & & & & & & $0.738^{* * *}$ & $0.337^{* * *}$ \\
\hline$R^{2}$ & 0.005 & 0.675 & 0.718 & 0.722 & -0.013 & 0.568 & 0.528 & 0.604 \\
\hline$\triangle R^{2}$ & & 0.670 & 0.043 & 0.004 & & 0.581 & 0.541 & 0.036 \\
\hline$F$ & 1.318 & $105.370^{* * *}$ & $110.552^{* * *}$ & $98.948^{* * *}$ & 0.234 & $67.036^{* * *}$ & $57.013^{* * *}$ & $66.513^{* * *}$ \\
\hline
\end{tabular}

For the test of the mediating role of academic Self-efficacy, model 2 shows that learning goal orientation has a significant positive effect on academic Self-efficacy $(\beta=0.817, p<0.01)$, while model 7 shows that academic Self-efficacy has a significant positive effect on academic satisfaction $(\beta=0.738, \mathrm{p}<0.01)$. Therefore, $\mathrm{H} 2$ and $\mathrm{H} 3$ were supported. As seen in Model 8, when academic goal orientation and academic Self-efficacy were included together in the regression equation, academic Self-efficacy had a significant positive predictive effect on academic satisfaction $(\beta=0.337, p<0.01)$, and the positive effect of academic goal orientation on academic satisfaction remained significant but became significantly smaller $(\beta=0.486, p<0.01)$. Thus, academic Self-efficacy partially mediates the predictive role of learning goal orientation on academic satisfaction, and $\mathrm{H} 4$ is supported.

Again, from Model 4, when the interaction terms of learning goal orientation, teacher academic support, and learning goal orientation and teacher academic support were included in the regression equation, learning goal orientation had a significant positive effect on academic Self-efficacy $(\beta=$ $0.534, \mathrm{p}<0.01)$, teacher academic support had a significant effect on academic Self-efficacy $(\beta=$ $0.285, \mathrm{p}<0.01)$, and teacher The interaction term consisting of academic support and learning goal orientation had a significant effect on academic Self-efficacy $(\beta=-0.102$, $p<0.01)$. Thus, teacher academic support plays a moderating role between learning goal orientation and academic Selfefficacy, and H5 is supported. 
For the process of teachers' academic support moderating learning goal orientation to academic Self-efficacy, this study further conducted Bootstrap test using Process plug-in and the results showed index $=-0.0466$, Boot standard error of 0.0197 , and confidence interval of $[-0.0853,-0.0079]$ at $95 \%$ level and did not contain 0 , that is Indirect effects of teacher academic support moderating learning goal orientation to academic Self-efficacy. Specifically, when teachers' academic support is high, the indirect effect value of teachers' academic support moderating learning goal orientation to academic Self-efficacy is 0.1658 with a confidence interval of $[0.0791,0.2828]$ at the $95 \%$ level and a confidence interval that does not contain 0 , indicating significance; when teachers' academic support is low, the corresponding indirect effect value is 0.2127 with a confidence interval of [0.0791, 0.2828] at the $95 \%$ level confidence interval was [0.0809, 0.3886], with a confidence interval that did not contain 0 , indicating significant.

\section{Analysis and Discussion}

\subsection{Research Conclusion}

In this study, the relationship between learning goal orientation, academic Self-efficacy and academic satisfaction under teachers' academic support was explored by means of an online questionnaire with college students as the research object, and the following conclusions were obtained: first, learning goal-oriented individuals have a higher academic Self-efficacy and can maintain a positive academic attitude in the face of difficulties, thus learning goal orientation positively predicts college students' academic satisfaction, which consistent with Roebken's study [12]; second, academic Self-efficacy has a significant positive relationship with academic satisfaction, which is consistent with the findings of other scholars [19] [7]. Third, academic Self-efficacy mediates the relationship between learning goal orientation and academic satisfaction; fourth, teacher academic support partially moderates the relationship between learning goal orientation and academic Self-efficacy, and the higher the teacher academic support, the more significant the positive relationship between learning goal orientation and academic Self-efficacy.

\subsection{Theoretical Contribution}

The theoretical contributions of this study are mainly reflected in the following two aspects. First, this paper further clarifies the positive relationship between learning goal orientation and academic satisfaction from the perspective of social cognitive theory, for which there are fewer previous studies. In addition, previous studies have focused on psychological capital as an explanatory mechanism [8] and then examined the path of learning goal orientation on academic satisfaction. This study leads to a new perspective on the relationship and enriches the research on learning goal orientation in the field of higher education. Second, this study proposes and empirically tests faculty academic support as a boundary condition between learning goal orientation and academic Self-efficacy. According to social cognitive theory, human behavior is influenced by individual cognitive and situational factors [15], and individuals' cognition and behavior differ in different contexts. In the case of learning goaloriented individuals, they are confident in their abilities and believe that they are variable [10]. For such individuals, the organizational context of academic support from teachers is more likely to produce higher academic Self-efficacy and contribute to academic satisfaction. Therefore, this study has a contribution to understanding how learning goal orientation affects academic satisfaction based on the perspective of social cognitive theory.

\subsection{Practical Implications}

The results of the study have important implications for universities and college students themselves to improve their academic satisfaction. From the school level, the school should improve the software and hardware facilities so as to improve the academic satisfaction of college students. Firstly, schools should equip strong teachers to ensure that students can enjoy quality educational resources; secondly, schools should provide good hardware facilities to ensure the smooth 
implementation of teaching activities; finally, schools should encourage teachers to take the initiative to provide academic support to students so as to increase students' confidence in overcoming difficulties. At the teacher level, teachers, as educators, should adopt the principles of inspiration and induction and tailor-made teaching to give students timely academic feedback and support, and cultivate a sense of belonging and identity. For students with high goal orientation, teachers should provide high academic support and encourage students to take on difficult tasks; for students with low goal orientation, teachers should carefully guide students and supervise them to complete their tasks on time. At the student level, students should see difficulties as opportunities, enhance their academic Self-efficacy, and actively seek academic support from teachers, ultimately increasing their academic satisfaction.

\subsection{Limitations and Future Research Directions}

There are certain limitations of this study. Firstly, this study mainly takes some college students in Jiangsu, Shanghai, Anhui and Sichuan as the empirical samples, and the data may be affected by regional factors. In the future, we can consider expanding the geographical coverage of the questionnaire to ensure the reliability and authenticity of the research and improve the external validity. Secondly, this study only focuses on the overall academic satisfaction, and more detailed entry points can be considered in the future, such as exploring the mechanism of the influence of learning goal orientation on learning satisfaction, teaching satisfaction and school hardware satisfaction. Finally, in this study, the relationship between learning goal orientation and academic Self-efficacy was only considered in terms of the moderating effect of teachers' academic support, and further studies based on academic emotions could be considered in the future.

\section{References}

[1] Yuan X. The relationship between self-regulated learning, procrastination and academic satisfaction among college students[D]. Henan University,2016.

[2] Zhang T. The relationship between college students' dormitory style and academic satisfaction[J]. China Metallurgical Education,2012(05):66-68+72.

[3] Franzen Jessica, Jermann Françoise, Ghisletta Paolo, Rudaz Serge, Bondolfi Guido, Tran Nguyen Toan. Psychological Distress and Well-Being among Students of Health Disciplines: The Importance of Academic Satisfaction.[J]. International journal of environmental research and public health,2021,18(4).

[4] Chang Z., Yang Y., Zheng Y. Model Construction of Influence Factors on Graduate Students' Academic Satisfaction --From the Socio-cognitive Perspective[J]. Educational Research,2013,34(08):96-102.

[5] Wang L. College students' procrastination and academic satisfaction: the mediating role of Self-efficacy [D]. Shandong Normal University,2019.

[6] Bao W. The Measurement and Determinants of Student Satisfaction in Higher Education Institution [J]. Research in Educational Development,2014,34(03):22-29+55.

[7] Zhang H., Song M., Gong H. The Influence of Social Support on College Students' Academic Satisfaction: The Mediating Effect of Academic Self-efficacy [J]. Journal of Pingdingshan University, 2021, 36 (03): 122-128.

[8] SánchezCardona Israel, OrtegaMaldonado Alberto, Salanova Marisa, Martínez Isabel M. Learning goal orientation and psychological capital among students: A pathway to academic satisfaction and performance [J]. Psychology in the Schools,2021,58(7):1432-1445.

[9] Ramos Alicia, De Fraine Bieke, Verschueren Karine. Learning goal orientation in high-ability and average-ability students: Developmental trajectories, contextual predictors, and long-term educational outcomes [J]. Journal of Educational Psychology,2021,113(2).

[10] Zhu J., Duan J., Tian X. Achievement Goal Orientation: Concept, Structure, Influencing Factors, and Consequences [J]. Psychology: Techniques and Applications,2016,4(08):499-508+512. 
Volume 3 (2021)

[11] Taing, M. U., Smith, T., Singla, N., Johnson, R.E., Chang., C. H. The relationship between learning goal orientation, goal setting, and performance: a longitudinal study[J]. Journal of Applied Social Psychology, 2013, 43(8):1668-1675.

[12] Roebken, H. (2007). Multiple Goals, Satisfaction, and Achievement in University Undergraduate Education: A Student Experience in the Research University (SERU) Project Research Paper. University of California at Berkeley, Center for Studies in Higher Education.

[13] Dweck, C S. Motivational Processes Affecting Learning[J]. American Psychologist, 1986, 41(10):10401048.

[14] VandeWalle, D, Cron, WL \& Slocum, JW. The Role of Goal Orientation Following Performance Feedback. Journal of Applied Psychology, 2001, 86(4):629-640.

[15] Bandura A. Social Foundations of Thought and Action: A social Cognitive Theory[M]. Englewood Cliffs: Prentice-Hall, 1986.

[16] Chi X. A study on the mechanism of teacher support's influence on college students' learning engagement based on self-determined motivation theory [D]. Tianjin University, 2017.

[17] Bandura, A. Self-efficacy: Toward a unifying theory of behavioral change. Psychological Review, 1977, 84 (2):191-215.

[18] Gong Y, Huang J C, \& Farh J L. Employee learning orientation, transformational leadership, and employee creativity: The mediating role of employee creative Self-efficacy[J]. The Academy of Management Journal, 2009, 52(4):765-778.

[19] Sivandani, A, Koohbanani, S.E., \& Vahidi, T. (2013). The Relation Between Social Support and Selfefficacy with Academic Achievement and School Satisfaction among Female Junior High School Students in Birjand. Procedia - Social and Behavioral Sciences,2013, 84(3):668-673.

[20] Artino, AR, Jr. Online Military Training: Using a Social Cognitive View of Motivation and SelfRegulation to Understand Students' Satisfaction, Perceived Learning, and Choice. Quarterly Review of Distance Education, 2007,8(3):191-202.

[21] Fu M., Ge M., Sang Q. Self - Efficacy and Social Anxiety of College Students [J]. Chinese Mental Health Journal,2005(07):45-46.

[22] Zhang Jing. A study on the relationship between social support, academic Self-efficacy and academic burnout among high school students [D]. Linfen: Shanxi Normal University, 2012.

[23] Xie L., Yang H., Zhang L., Zheng X., The Relationship between University Students' Academic Preparation and Academic Achievement: The Mediating Role of Interpersonal Interaction and Academic Self-efficacy [J]. Journal of Educational Studies,2020,16(01):83-91.

[24] Zhang W., Hu X. Influence Analysis of the Social Support and Academic Self-efficacy on the Subjective Well-being of Vocational College Students [J]. Journal of Jiangxi Science \& Technology Normal University,2016(04):105-110.

[25] Xhao F., Liu Y., Chen Y., Hu W. Multi-Decision Participation and Individual Innovation Performance: Role of Knowledge Sharing and Learning Goal Orientation [J]. Journal of Wuhan University of Technology (Social Sciences Edition),2021,34(02):74-82.

[26] Zhao X., Zhao X., Wang Y., Chen W. Achievement Goal Orientation as a Moderator in the Relationship between Job Demands and Job Strain [J]. Chinese Journal of Applied Psychology,2011,17(04):359$364+370$.

[27] Hidi, S \& Renninger, KA. The Four-Phase Model of Interest Development. Educational Psychologist, 2006, 41(2):111-127.

[28] Sakiz, G, Pape, SJ \& Hoy, AW. Does perceived teacher affective support matter for middle school students in mathematics classrooms? Journal of School Psychology, 2012, 50(2):235-255.

[29] Xing Q, Zheng C., Tang H., Xiao Y. The Influence of Teacher Autonomy Support on School Adjustment of Junior High School Students: a Moderated Mediated Model [J]. Educational measurement and evaluation, 2021(07):47-56.

[30] Wang D., Lu X., Yin X. The Association of Negative Academic Emotions on Perceived Academic Selfefficacy of Migrant Children: The Moderating Role of Emotion Regulation Strategies[J]. Psychological Development and Education,2017,33(01):56-64. 
Volume 3 (2021)

[31] VandeWalle, D. (1997). Development and validation of a work domain goal orientation instrument. Educational and Psychological Measurement, 57, 995-1015.

[32] Schwarzer R, Bäßler J, Kwiatek P, Schröder K, et al. The Assessment of Optimistic Self-beliefs: Comparison of the German, Spanish, and Chinese Versions of the General Self-efficacy Scale[J]. Applied Psychology, 1997,46(1):69-88.

[33] Alberto Ortega-Maldonado, Marisa Salanova. Psychological capital and performance among undergraduate students: the role of meaning-focused coping and satisfaction [J]. Teaching in Higher Education, 2018,23(3):390-402.

[34] Overall, N C, Deane, K L, \& Peterson, E R. Promoting doctoral students' research Self-efficacy: combining academic guidance with autonomy support[J]. Higher Education Research \& Development, 2011, 30(6):791-805. 